\title{
Experience of Supervised Internships, Focusing Attention on the Health of Pregnant Women
}

\author{
Tatiana Degani Paes Leme Azevedo ${ }^{1 *}$, Gabriela Mesquita Lopes ${ }^{1}$, Andréia de Aquino Marsiglio ${ }^{2}$ and Eric Jacomino Franco ${ }^{3}$
}

${ }^{1}$ Department of Pediatric Dentistry, School of Dentistry, Catholic University of Brasilia (CUB), Brazil

${ }^{2}$ Department of Dentistry, School of Dentistry, Catholic University of Brasilia (CUB), Brazil

${ }^{3}$ Department of Periodontology, School of Dentistry, Catholic University of Brasilia (CUB), Brazil

\begin{abstract}
This study aimed to relate the experience of structuring a supervised curricular internship program, focusing attention on the protocol used to promote oral health of pregnant women, at a Brazilian university. The internship was structured in 3 phases. The first consisted of conceptual construction, in which the students came in contact with the contextualization and theoretical grounding by means of debates, discussions about treatment protocols and interdisciplinary classes. The second phase followed, characterized by experience from the field. This phase was developed through practical action, using the protocols designed in the dental clinics of the university. Finally, there was a reflective phase in which the results of the practical experience were discussed. The proposal of this internship was able to attain the 3 pillars of university instruction: practice, teaching, and research.
\end{abstract}

Keywords: Pregnant women; Oral health promotion; Pregnancy

\section{Introduction}

The education of future dentists must be based on prioritizing attention toward universal and high quality health care, with emphasis on the promotion of health. In Brazil, the National Curricular Guidelines for Dental programs point to the relationship that curricular content should have with the entire wellness-illness process for the individual, the family, and the community. The guidelines also indicate a comprehensive education based on the connections among teaching, research, and practice.

In this way, in 2004 a program of dental care for pregnant women was introduced to provide care to the population through community service activities, and promoting actions focused on teaching and research. The objective was the comprehensive education of the student and the greater involvement of the university in the community. It is also notable that community service should be one of the functions of the university. keeping professors and students in contact with local and regional reality, rethinking the very university and redefining its role in the development of the region [1]. This complements the historic evolution of the dental curriculum, and points to the need for a dental generalist with paradoxical appreciation of the Biological Sciences and of technical skills at the expense of social education, occurring through the various reforms affected by political and social processes, involving different organizations and institutions of society [2]

Pregnancy is the ideal time to establish good habits because the pregnant woman appears psychologically receptive to acquiring new knowledge and to changing her patterns, which probably will have an influence on the development of the health of the baby [3-6]. Consequently, the fact that the woman is pregnant is no reason to postpone dental treatment [7-16].

Primary dental care during pregnancy should be understood, therefore, as being indispensable, prioritized and essential, the practice of which should be performed in teaching institutions responsible for the comprehensive education of the dental student. The development of concepts and practices directed toward the promotion of oral health [17-21] is also fundamental to the education of the students, allowing them to act as the modifying social agents within their sphere of influence.
In this context, it is accepted internationally that the promotion of health care directed toward pregnant women fosters health for the entire family, by means of the acquisition of healthy habits that are multiplied among all family members [22-30].

\section{Objective}

This study aimed to relate the experience of structuring a supervised curricular internship program, focusing attention on the protocol used to promote oral health of pregnant women, at a Brazilian university.

\section{Report of the Experience}

The study was approved by the Research Ethics Committee of the Catholic University of Brasilia (CUB).

The internship was structured in 3 phases. The first consisted of conceptual construction, in which the students came in contact with the contextualization and theoretical grounding by means of debates, discussions about treatment protocols and interdisciplinary classes.

The protocol for the treatment of pregnant women was organized as follows:

\section{First session}

- Filling out the questionnaire;

- Signing the Informed Consent;

- Medical History;

- Filling out the medical record, including the socioeconomic report;

*Corresponding author: Tatiana Degani Paes Leme Azevedo, Department of Pediatric Dentistry, Universidade Católica de Brasília, Brasília, Brazil, Tel: 011 55-61-3569612; 011-55-61-9161-6538; E-mail: degani@ucb.br; tdplazevedo@ hotmail.com; ericperio@gmail.com

Received December 10, 2011; Accepted April 19, 2012; Published April 25, 2012

Citation: Leme Azevedo TDP, Lopes GM, de Aquino Marsiglio A, Franco EJ (2012) Experience of Supervised Internships, Focusing Attention on the Health of Pregnant Women. Dentistry S10:002. doi:10.4172/2161-1122.S10-002

Copyright: (C) 2012 Leme Azevedo TDP, et al. This is an open-access article distributed under the terms of the Creative Commons Attribution License, which permits unrestricted use, distribution, and reproduction in any medium, provided the original author and source are credited. 
- Intra- and extra-oral physical examination;

- Instruction and Motivation in Oral Hygiene.

\section{Second session}

- Filling out the Periogram (periodontal probing, plaque index and gingival bleeding);

- Instruction and Motivation for Oral Hygiene;

- Prophylaxis;

- Filling out the Odontogram.

\section{Third session (will depend on each patient's needs)}

- Scaling and root planing, as necessary;

- Atraumatic Restorative Treatment (ART), as may be indicated, for the treatment of carious lesions;

- Instruction and Motivation in Oral Hygiene.

\section{Fourth session}

- Group lecture for all pregnant women, with the main focus on the promotion of oral health.

\section{Fifth session (every three months)}

- New collection of indices of plaque and gingival bleeding, for possible comparison with the first;

- Instruction and Motivation in Oral Hygiene.

With the completed clinical protocol, entry into the second phase followed, characterized by experience from the field. This phase was developed through practical action, using the protocols designed in the dental clinics of the university.

Finally, there was a reflective phase in which the results of the practical experience were discussed, including exchange of experiences and an evaluation of the activities registered in the portfolio. All the activities performed by the students were organized into a portfolio, in which they noted their impressions of all material studied, allowing their participation in the entire educational process. The use of a portfolio constitutes a recent practice of evaluation which considers students' development by means of reflection and impressions acquired throughout the entire learning process. This evaluative method is analyzed using a qualitative method.

\section{Discussion}

It was observed that the teaching methods integrated theory with practice, raising the level of learning among the students. Similar results were reported by Wilder et al. [31] who reinforced the fact that methods restricted to the classroom produced weak and inconsistent knowledge on the part of the students.

The ability to solve clinical problems and critical thinking were facilitated by prior access to information based on scientific evidence. Similar data were observed by Wilder et al. [31].

The research and the investigative spirit were present throughout the entire process, resulting in several studies presented at academic activities of the university, as well as conferences of the Brazilian Association of Dental Education (ABENO) and of the Brazilian Society of Dental Research (SBPqO).
Reports were found in the literature reflecting the positive experiences of mothers with their children's oral health: mothers who were satisfied with their own oral health gave greater importance to their children's oral health [28]. Interaction among doctors and pediatricians is essential to the discussion of new concepts about the promotion of health, giving early attention to the first year of life. The promotion of oral health among this group is extremely important, because it will guarantee improvement in their health and the creation of healthy habits for the babies.

Based on the findings, it was possible to conclude that the preventive program for pregnant women and babies was able to sensitize pregnant women to the importance of pre-natal dental care, and to motivate them in their role as the person responsible for their children's oral health, by introducing the habit of cleaning the baby's mouth and avoiding the development of carious lesions and harmful oral habits.

During the curricular revision proposed by the Program of Dentistry of the Catholic University of Brasilia, the development of this internship triggered its inclusion as a required discipline of supervised training at the clinic for the treatment of patients with special needs.

\section{Conclusion}

The proposal of this internship was able to attain the 3 pillars of university instruction: practice, teaching, and research. It also made it possible for the students and professors to offer better quality primary care, by means of procedures based on scientific evidence. Moreover, the practical experience allowed knowledge of the day-to-day reality, such as the future health professionals will have to face, and the consolidation of important skills and competencies as they build their professional identities.

\section{References}

1. Moura LF, Lira DM, Moura MS, Barros SS, Lopes TS, et al. (2001) Oral health preventive program for pregnant women and infants. J Bras Odontopediatr Odontol Bebe 4: 10-14

2. Silveira JL (2004) Diretrizes Curriculares Nacionais Para os Cursos de Graduação em Odontologia: Historicidade, Legalidade e Legitimidade. Pesq Bras Odontoped Clin Integr Joao Pessoa 4: 151-156.

3. Oliveira DM. Odontologia para gestantes. 2001, disponível em www. odontologia.com.br. Acesso em 10 de janeiro de 2010.

4. Elias R, Figueiredo MAZ, Yurguel L Atendimento Estomatológico em Gestantes - Verdades e Mitos. ABO Nac 2004.

5. Reis DM, Pitta DR, Ferreira HM, de Jesus MC, de Moraes ME, et al. (2010) Health education as a strategy for the promotion of oral health in the pregnancy period. Cien Saúde Colet 5: 269-276.

6. Kumar J, Samelson R (2009) Oral health care during pregnancy recommendations for oral health professionals. N Y State Dent J 75: 29-33.

7. Kanotra S, Sholapurkar AA, Pai KM (2010) Dental considerations in pregnancy: review. Rev Clín Pesq Odontol 6: 161-165.

8. Bonta CY; Cohen DW. Compendium de Educação Continuada em Odontologia - Mulheres e Odontologia. 2001.

9. Boggess KA, Urlaub DM, Massey KE, Moos MK, Matheson MB, et al. (2010) Oral hygiene practices and dental service utilization among pregnant women. $J$ Am Dent Assoc 141: 553-561.

10. Bassey GO, Anyanechi CE, Ekabua KJ, Ekabua JE (2010) Oral health among antenatal care attendees in Calabar, Nigeria. J Obstet Gynaecol 30: 143-146.

11. Keirse MJ, Plutzer K (2010) Women's attitudes to and perceptions of oral health and dental care during pregnancy. J Perinat Med 38: 3-8. 
Citation: Leme Azevedo TDP, Lopes GM, de Aquino Marsiglio A, Franco EJ (2012) Experience of Supervised Internships, Focusing Attention on the Health of Pregnant Women. Dentistry S10:002. doi:10.4172/2161-1122.S10-002

12. Barros BM, Moliterno LF (2001) Would a periodontal disease be a new risk factor to low weight premature infants? Rev bras Odontol 58: 256-260.

13. Zanata RL, Navaroo MF, Pereira JC, Franco EB, Lauris JR, et al. (2003) Effect of caries preventive measures directed to expectant mothers on caries experience in their children. Braz Dent J 14: 75-81.

14. Curran T (2009) The Chemung County Perinatal Dental Coalition. N Y State Dent J 75: 37-42.

15. Milgrom P, Sutherland M, Shirtcliff RM, Ludwig S, Smolen D (2010) Children's tooth decay in a public health program to encourage low-income pregnant women to utilize dental care. BMC Public Health 10: 76.

16. Figueredo CMS, Sampaio JN, Fischer RG (2001) A doença periodontal como mecanismo de indução ao parto prematuro de crianças com baixo peso.

17. Offenbacher S, Katz V, Fertik G, Collins J, Boyd D, et al. (1996) Periodontal infection as a possible risk factor for preterm low birth weight. J Periodontal 67: 1103-1113

18. Offenbacher S, Lin D, Strauss R, McKaig R, Irving J, et al. (2006) Effects of periodontal therapy during pregnancy on periodontal status, biologic parameters, and pregnancy outcomes: a pilot study. J Periodontol 77: 20112024.

19. Rakoto-Alson S, Tenenbaum H, Davideau JL (2010) Periodontal diseases, preterm births, and low birth weight: findings from a homogeneous cohort of women in Madagascar. J Periodontol 81: 205-213.

20. Sadatmansouri S, Sedighpoor N, Aghaloo M (2006) Effects of periodontal treatment phase I on birth term and birth weight. J Indian Soc Pedod Prev Dent 24: 23-26.

21. Michalowicz BS, Hodges JS, DiAngelis AJ, Lupo VR, Novak MJ, et al. (2006) Treatment of periodontal disease and the risk of preterm birth. N Engl $\mathrm{J}$ Med 355: 1885-1894.
22. Offenbacher S, Beck JD, Jared HL, Mauriello SM, Mendoza LC, et al. (2009) Effects of periodontal therapy on rate of preterm delivery: a randomized controlled trial. Obstet Gynecol 114: 551-559.

23. Bassani DG, Olinto MTA, Kreiger N (2007) Periodontal disease and perinatal outcomes: a case-control study. J Clin Periodontol 34: 31-39.

24. Armitage GC (1999) Development of a classification system for periodontal diseases and conditions. Ann Periodontol 4: 1-6.

25. Figuero E, Carrillo-de-Albornoz A, Herrera D, Bascones-Martínez A (2010) Gingival changes during pregnancy: I. Influence of hormonal variations on clinical and immunological parameters. J Clin Periodontol 37: 220-229.

26. Rosell FL, Montandon-Pompeu AA, Valsecki Júnior A (1999) Simplified periodontal record for pregnant women. Rev Saúde Publica 33: 157-162.

27. Dimitrova MM (2009) A study of pregnant women's knowledge of children's feeding practice as a risk factor for early childhood caries. Folia Med (Plovdiv) 51: $40-45$.

28. Reisine S, Douglass JM (1998) Psychosocial and behavioral issues in early childhood caries. Community Dent Oral Epidemiol 26: 32-44.

29. Barata TJ, Bresciani E, Mattos MC, Lauris JR, Ericson D, et al. (2008) Comparison of two minimally invasive methods on the longevity of glass ionomer cement restorations: short-term results of a pilot study. J Appl Oral Sci 16: 155-160.

30. Farag A, van der Sanden WJ, Abdelwahab H, Frencken JE (2011) Survival of ART restorations assessed using selected FDI and modified ART restoration criteria. Clin Oral Investig 15: 409-415.

31. Wilder RS, lacopino AM, Feldman CA, Guthmiller J, Linfante J, et al. (2009) Periodontal-systemic disease education in U.S. and Canadian dental schools. J Dent Educ 73: 38-52.
This article was originally published in a special issue, Infection Prevention \& Control in Dental Practice handled by Editor(s). Dr. Andrew Smith, University of Glasgow, UK 